\title{
A DISTRIBUIÇÃO DOS ESPAÇOS PÚBLICOS EM BELO HORIZONTE: UMA ANÁLISE SOB A ÓTICA DO DIREITO À CIDADE E DO PLANEJAMENTO URBANO
}

\author{
THE DISTRIBUTION OF PUBLIC SPACES IN BELO HORIZONTE: AN ANALYSIS FROM \\ THE PERSPECTIVE OF THE RIGHT TO THE CITY AND URBAN PLANNING
}

Kelly Silva ${ }^{1}$

\begin{abstract}
Resumo
O artigo analisa, qualitativa e quantitativamente, a aplicação de alguns conteúdos do Direito à Cidade em Belo Horizonte/MG, mormente aqueles que buscam garantir qualidade de vida à população e que convocam a população a participar da vida na cidade e a usufruir dos seus espaços, especialmente nos parques e praças. Previamente, é feita uma breve revisão da literatura sobre espaços públicos urbanos, direito à cidade e cidadania. O espaço público urbano organiza-se enquanto espaço de expressão e contestação de valores sociais, como terreno privilegiado de batalha entre diferentes formas de cidadania e modalidades para seu exercício. Por outro lado, percebe-se que há, historicamente, uma distribuição desigual da localização desses espaços no plano urbano, conforme variação do Índice de Desenvolvimento Humano - IDH das 9 regionais administrativas da cidade de Belo Horizonte. As noções de público, espaço público, esfera pública são construções normativas de um ideal de inclusão que inspiraram, em várias ocasiões, grupos marginalizados a lutarem por acesso, a tornarem-se parte. Percebe-se, por fim, que o acesso e a pertença à cidade e, consequentemente, 0 exercício da cidadania em todas as suas formas, convencionais ou não, por parte de grupos marginalizados e/ou suburbanos, pode encontrar vários óbices à sua efetivação.
\end{abstract}

Palavras-chave: Espaço Público Urbano; Direito à Cidade; Cidadania; Planejamento Urbano.

\section{Abstract}

The article analyzes, quantitatively and qualitatively, the application of some of the contents of the Right to the City in the city of Belo Horizonte/MG, especially those that seek to guarantee quality of life for the population and that call the population to participate in urban life and to enjoy its spaces, especially in parks and squares. Previously, it's presented a brief literature review about urban public spaces, the right to the city and citizenship. The urban public space is organized as a space for expression and contestation of social values, as a privileged terrain of battle between different forms of citizenship and modalities for its exercise. In other hand, historically, there is an unequal distribution of the location of these spaces in the urban plan, according to the Human Development Index - HDI variation of the 9 administrative regions in Belo Horizonte city. The notions of the public, public space, public sphere are normative constructions of an ideal of inclusion that have inspired, on several occasions, marginalized groups to struggle for access, to become a part of the city. It's noticed that access and belonging to the city and, consequently, the exercise of citizenship in all its forms, conventional or not, by marginalized and/or suburban groups may find several obstacles to its realization.

Keywords: Urban Public Space; Right to the City; Citizenship; Urban Planning.

\footnotetext{
${ }^{1}$ Doutoranda em Geografia (Instituto de Geociências/UFMG). E-mail: kelinabh@yahoo.com.br
} 


\section{INTRODUÇÃO}

O artigo analisa, qualitativa e quantitativamente, a relação do indivíduo com o espaço público urbano, valendo-se de alguns conteúdos do Direito à Cidade, em especial aqueles que buscam garantir qualidade de vida à população e que convocam a população a participar da vida na cidade e a usufruir dos seus espaços, tendo como local de estudo os parques e as praças da cidade de Belo Horizonte/MG.

Previamente, é feita uma breve revisão da literatura sobre espaços públicos urbanos, cidadania e direito à cidade para clarificar a importância desses espaços como elementos geradores de vitalidade urbana uma vez que propiciam o encontro com o outro; a frequência, a utilização, a apropriação desses espaços pela população e as trocas ali efetuadas são meios de construção e exercício da cidadania e fazem parte do conteúdo do Direito à Cidade.

O espaço público urbano organiza-se enquanto espaço de expressão e contestação de valores sociais, como terreno privilegiado de batalha entre diferentes formas de cidadania e modalidades para seu exercício. A verdadeira cidade, para Rousseau, não era mera urbs - um aglomerado de casas - antes deveria sempre ser polis, ou seja, guardar uma dimensão política (VIEIRA, 2008, p. 84). A função tradicional do espaço da cidade é como local de encontro e fórum social para o exercício da cidadania, lugar de manifestações inusitadas de indivíduos, da materialização das trocas e de reprodução da vida cotidiana. Sob uma perspectiva histórica, o espaço da cidade funcionou como ponto de encontro para os moradores em vários níveis, sendo as praças e os parques - espaços públicos tradicionalmente relacionados com o lazer, entretenimento, diversão, esportes e descanso - lugares que deveriam favorecer tal encontro.

Faz-se, em seguida, uma análise da distribuição dos parques e praças em Belo Horizonte - aproveitando pesquisa de campo em andamento que busca aferir o usufruto e vivência desses espaços -, a fim de demonstrar o déficit de Direito à Cidade e cidadania verificados em áreas periféricas da cidade e como o Estado - principal agente interventor ou fomentador de intervenções - poderia mitigar ou estimular tal lacuna.

Em uma cidade convivem, partilham ou dividem espaços uma diversidade de identidades urbanas, culturas/subculturas e grupos de interesse envolvidos, todos com direitos e deveres; contudo, em que pese o Direito à Cidade abarcar todos os seus espaços e preconizar uma participação democrática e usufruto equitativo da vida urbana - o que envolve um bom planejamento - percebe-se também lugares mais vivos e dinâmicos e outros menos. Vale dizer que o Estatuto da Cidade, em seu artigo 2, I, entende como Direito à Cidade "o direito à terra 
urbana, à moradia, ao saneamento ambiental, à infraestrutura urbana, ao transporte e aos serviços públicos, ao trabalho e ao lazer (...)".

\section{ESPAÇOS PÚBLICOS URBANOS - PRAÇAS E PARQUES}

As praças e os parques são espaços públicos tradicionais das cidades modernas. A praça pode ser caracterizada como um espaço destinado à convivência das pessoas, reuniões fortuitas e para o exercício da vida pública (de moradores ou não), em um ambiente urbano livre de edificações convencionais. ${ }^{2}$

Em seus estudos sobre praças contemporâneas no Brasil, Robba e Macedo consideram duas premissas básicas para conceituar tais espaços: uso e acessibilidade, conceituando-as como "espaços livres urbanos destinados ao lazer e ao convívio da população, acessíveis aos cidadãos e livres de veículos" (ROBBA; MACEDO, 2002). Essa tipologia mantém o caráter de sociabilidade que é intrínseco às funções da praça, descartando-se alguns logradouros públicos enquadrados como tal e que nada mais são do que canteiros centrais, rotatórias, restos de sistemas viários gramados não oferecendo condições mínimas adequadas ao exercício do lazer ou acessibilidade da população.

Quanto maior a concentração de praças, quanto mais apropriadas de maneiras diversas, quanto mais usos e significados, quanto mais intricadas as histórias individuais e coletivas, maior o potencial de centralidade dessas áreas nos planos simbólico e lúdico. Assim, no caso das praças de bairro, quando apresentam tal plurissignificação e utilização consolidamse como elemento que sintetiza e afirma a identidade local, assumem um caráter de centralidade (BRASIL, 1993, p. 168).

O parque urbano, por sua vez, é um produto da cidade da era industrial e veio para supri-la de espaços para a nova demanda da sociedade, qual seja, o lazer e o ócio. Uma cidade com mais áreas de lazer traduziria um estilo urbano mais agradável. Mas o que seria um parque público urbano? Pode-se considerá-lo todo espaço de uso público destinado à recreação de

\footnotetext{
${ }^{2}$ Esse espaço para os gregos era a ágora, local onde o exercício da cidadania se materializava representando o espírito de coletividade da população. Lá se praticava a democracia direta, debatiam-se ideias, eram discutidos os negócios e decididos os rumos da cidade. Por meio de assembleias e com direito igual a voto, os cidadãos eram ouvidos. Tratava-se de um espaço delimitado por edificações diversas de caráter público e conjunto de pórticos ou colunatas abertas ao público onde os mercadores em feiras livres podiam comercializar seus produtos. Já para os romanos, era o Fórum o espaço livre público central das relações sociais, das atividades comerciais, religiosas e de mercado. Marcava o centro comercial da Roma imperial e era configurado por imponentes edifícios públicos que representavam a monumentalidade do Estado. As discussões políticas aconteciam não nas praças abertas, mas no interior dos edifícios.
} 
massa e que possa incorporar diretrizes de conservação.

O parque se destaca como um espaço privilegiado de estar e fazer cidade, espaço para descobrir implicações emocionais significativas entre corpo, espaço público e urbanidade a partir dos imaginários que o vinculam com a urbanização, relaxamento, natureza e prazer (FIGUEROA, 2006, p. 149).

No que tange às variáveis ambientais dos índices de qualidade de vida, a arborização de parques e praças incorpora importantes fatores de estabilização ecológica e ambiental. Reduz os efeitos da poluição e de rigores microclimáticos causadores de desconforto (grande amplitude térmica durante o dia com altas temperaturas) e ajuda a regular a umidade relativa do ar (todos esses fatores trazem prejuízos à saúde). Pesquisas sobre ilhas de calor revelam que a temperatura pode oscilar entre 7 e 10 graus comparativamente a áreas com grande quantidade de vegetação arbórea (CALOR, 2009, p.31). O potencial do parque urbano estaria principalmente nos serviços ambientais que presta ao seu entorno imediato (manutenção da biodiversidade, drenagem de águas pluviais, regulação microclimática, equilíbrio ecológico, qualidade do ar) (MACHADO, 2009, p.91). Fato é que a qualidade ambiental urbana angaria cada vez maior destaque nas discussões acadêmicas, políticas e sociais, sobretudo se relacionadas aos conceitos de desenvolvimento sustentável e de sustentabilidade urbana.

Não obstante, é relevante ponderar que além da quantidade desses espaços em uma cidade - fato analisado neste artigo quando se fala da distribuição dos espaços públicos de lazer em Belo Horizonte - importa também a qualidade, a frequência de usuários nesses espaços, a permanência das pessoas no local e as trocas, principalmente entre grupos heterogêneos.

\section{CIDADANIA}

Na tradição do pensamento político ocidental, há uma associação estreita entre cidadão e pertença à cidade; não obstante, observa-se que é variável a capacidade com que cada indivíduo/grupo se responsabiliza pela evolução da cidade. Estariam os direitos/deveres de cidadania e de participação mais imbuídos em alguns grupos que em outros? Ou a construção/organização do espaço da cidade tenderia a favorecer determinadas camadas da população? Na verdade, essas variáveis se encontram imbricadas.

Ser cidadão significa ter direitos e deveres, ser súdito e ser soberano. Tal situação está descrita na Carta de Direitos da Organização das Nações Unidas, de 1948, que tem suas primeiras matizes marcantes nas cartas de Direito dos Estados Unidos - 1776 - e na Revolução 
Francesa -1798 - (COVRE, 1995, p.9). Porém há que se ponderar que não se nasce com igualdade em dignidade e direito, então a cidadania consistiria no direito a ter direitos (ARENDT, 1989). O exercício da cidadania seria "construído da convivência coletiva, que requer o acesso a um espaço público comum (...) é esse acesso ao espaço público (...) que permite a construção de um mundo comum através do processo de asserção dos direitos humanos" (LAFER, 1988).

Verifica-se, hoje em dia, uma alteração crescente na forma de exercício da cidadania: além das formas convencionais (voto, partidos políticos, sindicatos, cooperativas, igrejas, associações), há outras modalidades mais fluidas e multidimensionais de mobilização e envolvimento (organizações não formais, manifestações, petições e debates online ${ }^{3}$, mas que pressupõem, também, mobilização cognitiva mais acentuada, isto é, maior convencimento individual acerca da política, com disposição para influenciar outras pessoas) (VIEIRA, 2008, p.91).

Para DaMatta, supercidadania e subcidadania seriam variáveis dependentes do espaço social onde a pessoa se encontra. Assim, no âmbito espacial, para este autor (DAMATTA, 1997, p.30 e ss), haveria três diferentes perspectivas, complementares entre si e com diferentes éticas sociais ${ }^{4}$ : a casa (o privado, mais conservador), a rua (o público, o espaço público, aberto ao legalismo jurídico, mercado) e o outro mundo. A cada espaço corresponderiam, então, atitudes, gestos, assuntos e papéis sociais distintos e cada evento seria sempre interpretado por meio do código casa, rua ou outro mundo, ou seja, a relação desempenharia um papel crítico na concepção e na dinâmica da ordem social. A oposição casa/rua seria dinâmica e relativa. Para o autor, as camadas 'dominadas' tenderiam a usar como fonte de interpretação o código da casa, já segmentos dominantes tenderiam a fazer a leitura pelo código da rua. Ainda de acordo com DaMatta, o espaço público seria perigoso e representaria em princípio o negativo, pois fundado no descaso e na linguagem da lei, que, igualando, subordinaria e exploraria, além de criar deveres e obrigações. Assim, para DaMatta, ainda que o papel de cidadão faça parte do ideário da ética pública e que o exercício da cidadania esteja previsto na legislação (a rua), no cotidiano, a rede de relações pessoais para mediações tradicionais ainda apareceria bastante forte (a casa).

\footnotetext{
${ }^{3}$ No caso da internet como espaço público, importante frisar que esta não diminui a importância da interação face a face, considerando-se a possibilidade do anonimato naquela, o não acesso a vários desfavorecidos, etc.

${ }^{4} \mathrm{O}$ autor, citando Weber, comenta que diferentes éticas sociais caracterizariam uma sociedade tradicional, sendo que com a passagem desta para o capitalismo fez-se necessário a adoção de uma ética única, com um único modo de avaliação moral, tornando o comércio positivo e universal.
} 
Jessé de Souza (SOUZA, 2015, p. 84 e ss) contra-argumenta, porém, que independentemente do lugar ou do espaço social em que se encontram, todos os grupos sociais oprimidos enfrentariam situações de subcidadania. Para o autor, a hierarquia social de qualquer sociedade moderna só pode ser compreendida a partir de sua contribuição à reprodução do Estado e do Mercado. Há que se tentar perceber como a dinâmica coletiva influencia no comportamento individual. Em DaMatta, somente se encontram indivíduos/espaços sociais e não estratificação social; assim, valores passam a ser concebidos como algo que existe independentemente de sua institucionalização (do Estado e/ou do Mercado), agindo de forma misteriosa sobre indivíduos e espaços sociais (SOUZA, 2015, p.80). O indivíduo que DaMatta fala não existiria, então, somente na 'rua' uma vez que entraria em nossas casas e nos diria, em grande medida, como deveríamos agir, o que deveríamos desejar e como deveríamos nos sentir.

Além disso, o acesso a relações pessoais de prestígio (que DaMatta coloca como se tivesse lugar no plano da casa) só existiria, na verdade, para quem já possui acesso a capitais impessoais, conforme terminologia de Pierre Bourdieu. Os capitais impessoais, segundo Bourdieu, seriam o capital econômico e cultural, que são elementos estruturantes de toda a hierarquia social moderna (SOUZA, 2015, p.153 e ss), abrindo portas e se impondo também por meio da violência simbólica ${ }^{5}$. Quem detém capital econômico detém quase sempre capital social ('jeitinho', relações privilegiadas de DaMatta). O capital cultural - conhecimento permite a ocupação de boas funções tanto no Estado quanto no Mercado. Portanto, o acesso a esses capitais - econômico e cultural - define o acesso privilegiado e define também quem terá acesso ao capital social, que seria a capacidade de percepção, apropriação e de valorização de determinados valores cívicos por parte de uma comunidade - que são vinculados a estruturas e redes de inclusão e exclusão sócio-territorial.

Vale dizer que, normalmente, todos esses capitais andam juntos em proporção variável. Percebe-se, também, que a mobilização cívica é maior quando há maior renda, instrução e mobilização congnitiva dos indivíduos (VIEIRA, 2008, p.98).

As cidades são, como dito outrora, locais de interação e troca permanente, ainda que anônima, entre um público heterogêneo, de uma massa densa e incerta de pessoas. Para tais trocas, pressupõe-se a existência de espaços coletivos onde o encontro entre estranhos seja

\footnotetext{
${ }^{5} \mathrm{~A}$ ideologia da meritocracia esconde sistematicamente a produção social dos desempenhos diferenciais entre os indivíduos, tornando possível que o desempeho diferencial "apareça" como diferença de talentos inatos (SOUZA, 2015, pp 154).
} 
comum. Há, pois, uma associação entre frequência do espaço público e os traços psicológicos típicos de um urbanita ${ }^{6}$. O espaço público urbano é, então, um espaço de incerteza, de risco, fomentando o estímulo e a aprendizagem mútua (VIEIRA, 2008, p. 102). Contudo, as noções de público, espaço público, esfera pública são construções normativas de um ideal de inclusão e que inspirou, em várias ocasiões, grupos marginalizados a lutarem por acesso, a tornarem-se parte.

Mas a simples dicotomia exclusão/inclusão não faz jus à complexa estrutura piramidal, admitindo graus intermediários, que caracterizaria a cidadania dentro de cada Estado. A existência urbana pressupõe heterogeneidade, seja religiosa, étnica, sócio-cultural, propiciando guerras culturais ligadas às identidades e à reivindicação e uma cidadania diferenciada ${ }^{7}$ (VIEIRA, 2008, p. 92).

Por sua vez, a suburbanização, bastante obvervada nas cidades brasileiras, trouxe consigo, em muitos casos, uma maior separação casa-trabalho (recrudescimento dos fluxos pendulares) e uma maior segregação sócio-espacial entre diferentes classes, o que pode gerar externalidades negativas no que tange à intensidade da interação social informal e do envolvimento cívico do indivíduo: o primeiro motivo é porque esta dispersão espacial é custosa em termos temporais, ou seja, o grande dispêndio de tempo do indivíduo no trajeto casaescola-trabalho reduz sua disponibilidade para participar, envolver-se na vida da cidade, ou outras reivindicações e lutas, como também a usufruir de seus espaços; em segundo lugar, a segregação do espaço entre grupos homogêneos reduz a possibilidade de integração entre grupos heterogêneos, isto é, o espaço da cidade é construído e ocupado de maneira tal que dificulta o encontro entre diferentes, o que pode acarretar, ainda, uma diminuição sobre os níveis de inclusão/solidariedade entre os diferentes grupos.

\section{DIREITO À CIDADE - DISTRIBUIÇÃO DE PARQUES E PRAÇAS EM BELO HORIZONTE}

Considerando que o exercício da cidadania, como dito acima, acontece no cotidiano e na ocupação da cidade por diferentes grupos, faz-se necessário garantir meios de tornar possível essa apropriação pelos indivíduos, ainda que tal processo seja de mão dupla, ou seja, a luta por direitos e diferentes formas de cidadania necessita de espaços de expressão e

\footnotetext{
${ }^{6}$ No sec XVIII, cosmopolite era o indivíduo que circulava confortavelmente na diversidade, que encontrava nos novos equipamentos urbanos - parques, praças, ruas peatonais - seu habitat.

7 Importante frisar a tensão que esta cidadania diferenciada pode gerar com a concepção moderna de cidadania de base igualitária. Não obstante, faz-se necessário ponderar que dada as condições desiguais de determinados grupos sociais, a concepção igualitária camuflaria tal desigualdade, perpetuando-a.
} 
contestação e a existência desses espaços favorece o exercício da cidadania. Essa apropriação do espaço público faz parte do conteúdo do Direito à Cidade.

A expressão de Henri Lefebvre 'Direito à Cidade' circula em discussões, publicações (tais como a Carta Mundial pelo Direito à Cidade), eventos, conferências (eg, Rightstothe City: Citizenship, Democracy and Cities in a Global Age), movimentos (por exemplo, o RechtaufStadtNetzwerk) e legislações, tanto nacionais quanto internacionais, acadêmicos ou não.

O 'Direito à Cidade' lefebvriano residia na tomada de suas ruas, no exercício de apropriação de seus espaços, na apropriação da cidade por seus habitantes, possibilitando a vivência urbana por completo. É na vida cotidiana que os espaços, além de construídos e percebidos são, de fato, vividos. Para Lefebvre, o Direito à própria cidade, aos seus espaços coletivos públicos, nunca se encontra garantido, exigindo permanente vigilância, luta e participação. Sendo o homem um ser político, a 'cidade' seria conditio sinequa non à sua existência humana e, sua capacidade de fala, discurso, retórica e discernimento entre o bem e o mal seria necessária em sua interação com a cidade (ARISTÓTELES, acesso digital, p.12). Para Monte-Mór, 'direito à cidade' seria fazer do espaço urbano um locus privilegiado da tríade articuladora da vida social urbana: Poder Político, Excedente Econômico e a Festa (MONTEMÓR, 2006, n. 281).

No Brasil, o Seminário de Habitação e Reforma Urbana de 1963 fez nascer a ideia de reforma urbana como resposta à crise urbana (KAPP, 2012, p.465); dessa ideia surgiu a Emenda Popular da Reforma Urbana, que restou em parte acatada nos artigos 182 e 183 da Constituição da República em 1988. A Constituição, porém, não esclarece qual seria o conteúdo de um 'Direito à Cidade', mas sim atribui funções à cidade (e em última análise ao Poder Público) e aos que nela habitam e exercem atividades.

A positivação do Direito à Cidade Sustentável (posto que para as presentes e para as futuras gerações), com delimitação de perspectiva, deu-se com a edição da Lei 10257/2001, o Estatuto da Cidade. Em seu artigo 2, I, este é entendido como "o direito à terra urbana, à moradia, ao saneamento ambiental, à infraestrutura urbana, ao transporte e aos serviços públicos, ao trabalho e ao $\operatorname{lazer}^{8}(\ldots)^{\prime \prime}$.

\footnotetext{
${ }^{8}$ Há autores que consideram que hoje o lazer seria mediado pela mercadoria como, por exemplo, Ana Fani Carlos (CARLOS, 2015 p.40), o que levaria o indivíduo a não mais se apropriar socialmente da cidade por meio de brincadeiras, jogos e ócio, mas sim consumir sua diversão como em shoppings, espetáculos e feiras, entre outros, não mais simplesmente desfrutando do espaço em si como em campos de futebol de várzea, parques, praças, regatas em lagos e rios. Nessa mesma linha, Fortuna e Silva (FORTUNA; SILVA, 2002) alegam que existe um forte movimento de privatização e comercialização das atividades culturais,
} 
Vale ainda mencionar que o Estatuto da Cidade prevê várias diretrizes - algumas abaixo elencadas - e instrumentos para sua consecução, quais sejam: a) planos nacionais, regionais e estaduais de ordenação do território e de desenvolvimento econômico e social; b) planejamento das regiões metropolitanas, aglomerações urbanas e microrregiões; c) planejamento municipal (como os planos diretores, zoneamento, uso e ocupação do solo); d) institutos tributários e financeiros (como IPTU, contribuição de melhoria) ; e) institutos jurídicos e políticos (como desapropriações, tombamento, preempção, referendo, plebiscito); f) estudo prévio de impacto ambiental (EIA) e estudo prévio de impacto de vizinhança (EIV).

Art. 2ㅇ A política urbana tem por objetivo ordenar o pleno desenvolvimento das funções sociais da cidade e da propriedade urbana, mediante as seguintes diretrizes gerais:

I - garantia do direito a cidades sustentáveis, entendido como o direito à terra urbana, à moradia, ao saneamento ambiental, à infra-estrutura urbana, ao transporte e aos serviços públicos, ao trabalho e ao lazer, para as presentes e futuras gerações;

$(\ldots)$

$V$ - oferta de equipamentos urbanos e comunitários, transporte e serviços públicos adequados aos interesses e necessidades da população e às características locais;

$(\ldots)$

IX - justa distribuição dos benefícios e ônus decorrentes do processo de urbanização;

$X$ - adequação dos instrumentos de política econômica, tributária e financeira e dos gastos públicos aos objetivos do desenvolvimento urbano, de modo a privilegiar os investimentos geradores de bem-estar geral e a fruição dos bens pelos diferentes segmentos sociais;

(...)

XII - proteção, preservação e recuperação do meio ambiente natural e construído, do patrimônio cultural, histórico, artístico, paisagístico e arqueológico;

Art. 25. O direito de preempção confere ao Poder Público municipal preferência para aquisição de imóvel urbano objeto de alienação onerosa entre particulares.

$\S 1$ 으 Lei municipal, baseada no plano diretor, delimitará as áreas em que incidirá o direito de preempção e fixará prazo de vigência, não superior a cinco anos, renovável a partir de um ano após o decurso do prazo inicial de vigência.

Art. 26. O direito de preempção será exercido sempre que o Poder Público necessitar de áreas para: (...)

VI - criação de espaços públicos de lazer e áreas verdes;(Estatuto da Cidade, Lei 10.257/2001)

já que o lazer, a cultura e a diversão tornaram-se bastante lucrativos na cidade pós-industrial. Flávia Brasil, por sua vez, argumenta que o lazer manifesta-se como uma prática específica de diversos grupos sociais, sendo que na escala individual e do cotidiano, pode-se observar, por exemplo, a apropriação das praças como lugar de descanso, exercício de atividades físicas, jogos e contatos interpessoais, não assumindo características do lazer mercantilizado (BRASIL, 1993). 
Trata-se, pois, de conteúdo dinâmico, evolutivo e variável ${ }^{9}$, cujos elementos podem apresentar alguma rivalidade (em um contexto de escassez de recursos, isto é, quando faz-se necessário fatiar o orçamento - limitado - entre várias áreas de interesse) ou complementariedade. Não obstante, ainda que o art. 20 fale em diretrizes gerais, elas ratificam alguma autonomia do Poder Público no que tange à escolha dos meios para se atingirem os fins consagrados no plano normativo, sendo o conteúdo do direito à cidade relativamente aberto.

A rivalidade supramencionada revela-se quando, por exemplo, dentre várias necessidades postas, em áreas e temas diversos na cidade, há uma dependência de uma deliberação política acerca de onde serão alocados recursos. A composição dos interesses em jogo - com opções técnicas, políticas e jurídicas - e o poder dos atores envolvidos pode levar, e frequentemente leva, a certa preferência de alguns elementos/áreas em detrimento de outros (MARICATO, 2011, p.77), ou seja, no caso de parques e praças, o discurso oficial defende a ideia de que toda a população será beneficiada, mas na prática percebe-se que 'uns são mais iguais que os outros'.

Assim, pode-se dizer que a distribuição atual dos equipamentos públicos, infraestruturas, áreas de lazer, entre outros, em uma cidade refletem como se deu a composição dos diversos interesses no decorrer dos anos; pode-se ainda dizer que há uma ecologia de bairros que corresponde a uma ecologia de classes sociais (SENNET, apud SERPA, 2014 p.51). Ou, nas palavras de Ana Fani Carlos, "o uso do solo ligado a momentos particulares do processo de produção das relações capitalistas é o modo de ocupação de determinado lugar da cidade"(CARLOS, 2015, p.45).

A Figura 1, com o histórico da criação de parques ${ }^{10}$ nas 9 regiões administrativas da cidade de Belo Horizonte, traduz o acima dito:

\section{Figura 1 - Evolução da criação de parques por regional administrativa em Belo Horizonte - jul/2016}

\footnotetext{
${ }^{9}$ Sendo de conteúdo abstrato, variando conforme a política urbana no âmbito de cada município, nas palavras de Guilherme Reisdorfer (REISDORFER, 2015 p.183), "até que ponto existiria um direito à cidade com posições jurídicas consolidadas e que apresente conteúdo estável e juridicamente exigível em relação ao conjunto de elementos que o compõem?"

10 Parques já implantados e abertos ao público, ainda que alguns não oficialmente inaugurados, totalizando 61.
} 


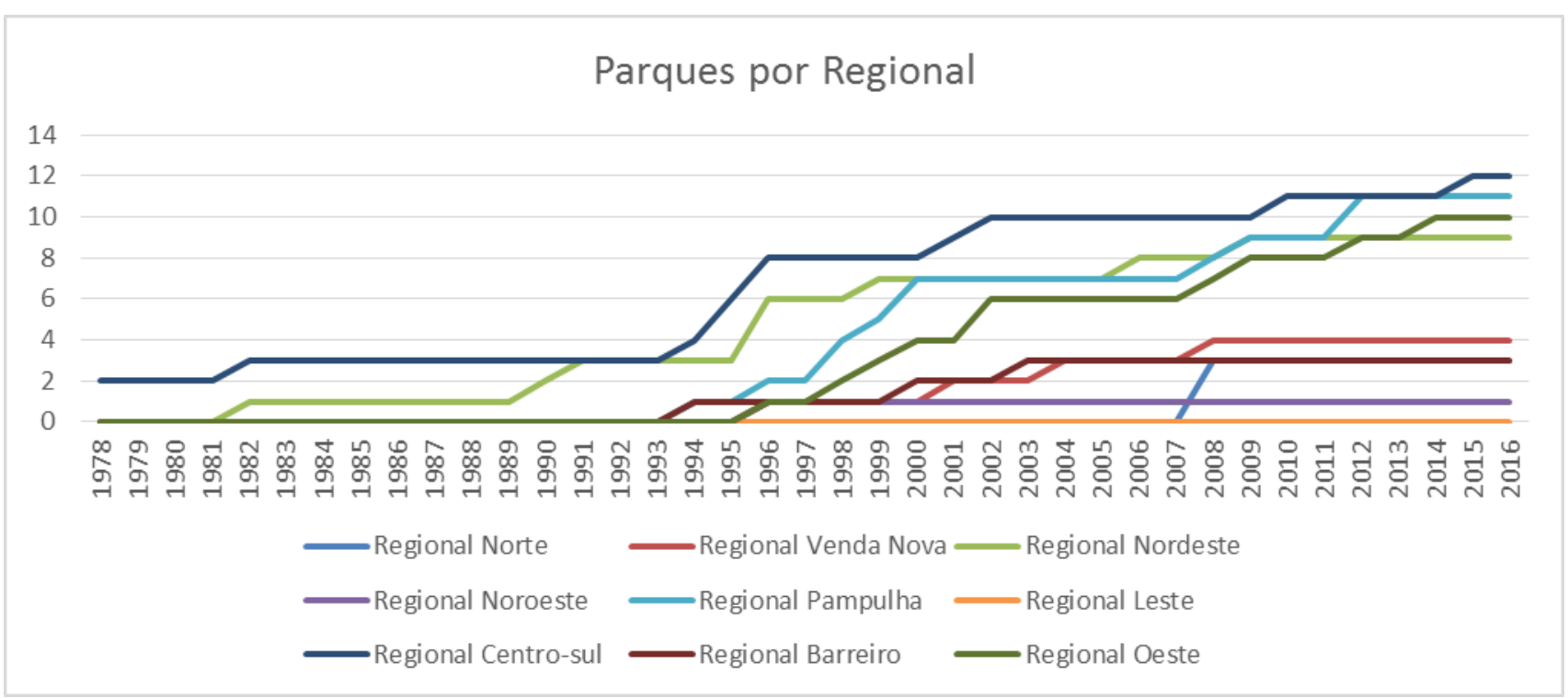

Fonte: Elaboração própria a partir de dados da Fundação de Parques Municipais

Como se pode depreender, o boom da criação dos parques na cidade ocorreu a partir de meados dos anos 90, sendo que algumas regionais são nitidamente mais favorecidas que outras no quesito número de parques, área destinada ao lazer e à recreação por habitante, notadamente a Regional Centro-Sul e a Pampulha. Em 2005, quando a Fundação de Parques Municipais - FPM - foi criada a maioria dos parques já existia.

Ainda para ilustrar a questão, verifica-se, conforme a Tabela 1, que as 9 regionais são diferenciadas em tamanho, população e qualidade de vida. Assim, combinando o Índice de Desenvolvimento Humano Municipal - IDHM da regional, área dos parques e população, tem-se que as maiores razões (áreas de parque por população) acompanham os 3 maiores IDHM médios por regionais em 2010, que são das Regionais Centro-sul, Pampulha e Oeste.

Tabela 1- Área por habitante e IDHM das Regionais de Belo Horizonte - 2010 \begin{tabular}{l|l|l|l} 
Regionais & Idhm (2010) & Área por habitante
\end{tabular} 


\begin{tabular}{|c|c|c|}
\hline Barreiro & 0,744 & 1,18 \\
\hline Centro-sul & 0,914 & 11,67 \\
\hline Leste & 0,827 & 0,22 \\
\hline Nordeste & 0,801 & 1,49 \\
\hline Noroeste & 0,818 & 0,40 \\
\hline Norte & 0,754 & 0,68 \\
\hline Oeste & 0,839 & 3,35 \\
\hline Pampulha & 0,853 & 4,5 \\
\hline Venda nova & 0,755 & 0,17 \\
\hline
\end{tabular}

Fonte: Elaboração própria a partir de dados do Atlas do Desenvolvimento Humano na RM Belo Horizonte e da FPM.

Já considerando o tamanho da regional e a quantidade de área verde disponível verifica-se pela Tabela 2 que novamente a Regional Centro-Sul destaca-se, mas de maneira muito expressiva em relação às demais. Isso se explica principalmente por ter uma menor superfície geográfica em relação às demais.

Tabela 2 - Área em $\mathrm{m}^{2}$ das Regionais e dos parques implantados abertos ao público e percentagem da área dos parques

\begin{tabular}{|c|c|c|c|}
\hline Regionais & Área dos parques & Área das regionais & Percentagem da área dos parques \\
\hline Barreiro & 335700 & 53.898 .700 & 0,62 \\
\hline Centro-sul & 3314200 & 32.622 .400 & 10,15 \\
\hline Leste & 53200 & 28.150 .700 & 0,19 \\
\hline Nordeste & 432800 & 39.519 .900 & 1,09 \\
\hline Noroeste & 109100 & 29.935 .900 & 0,36 \\
\hline Norte & 145700 & 32.780 .800 & 0,44 \\
\hline Oeste & 1035471 & 35.157 .000 & 2,94 \\
\hline Pampulha & 1019080 & 51.192 .900 & 1,99 \\
\hline Venda nova & 47500 & 29.110 .300 & 0,16 \\
\hline Total & 6493451 & 332.368 .600 & 1,95 \\
\hline \multicolumn{3}{|c|}{ Fonte: elaboração própria a partir de dados coletados junto à Prefeitura. } \\
\hline \multicolumn{3}{|c|}{} \\
\hline
\end{tabular}

As praças localizadas nas três regionais de menor IDHM totalizam 87 na Regional Norte, 94 na Regional Barreiro e 95 na Regional Venda Nova. Não obstante o significativo número, se se volta à função precípua das praças como espaço que possibilite e convide ao encontro e o lazer, percebe-se que, no caso dessas três regionais, localizadas na periferia de Belo Horizonte, a população do entorno pouco as utiliza com o intuito de lazer, preferindo para tal os parques. Ao serem questionados em pesquisa de campo realizada, muitos alegaram a ausência de atrativos, de sombra e também a questão da segurança, devido à presença de moradores de rua, mendicância e usuários de drogas, fato realmente observado durante a pesquisa. 


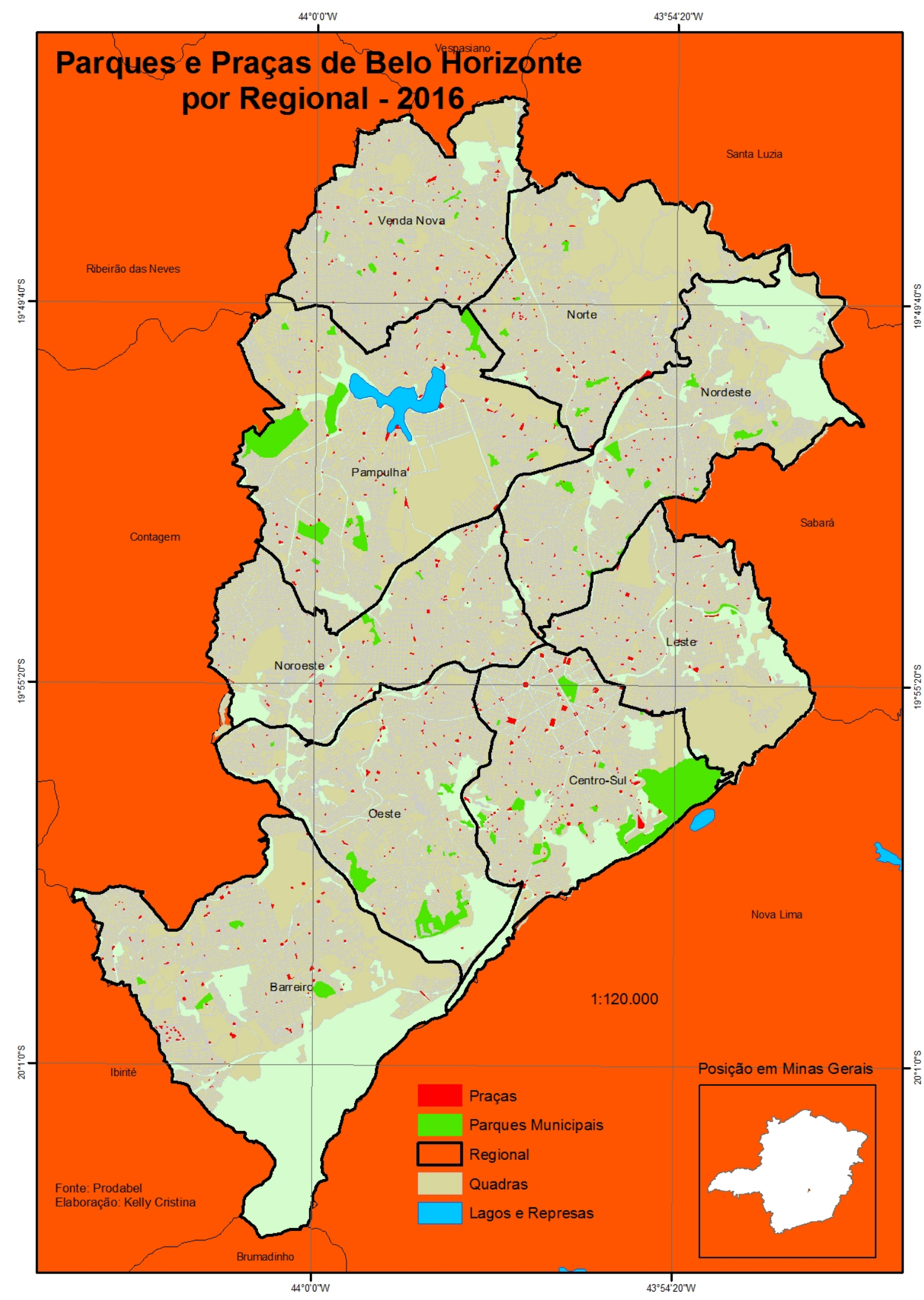


Faz-se necessário observar, não obstante, que para além da tutela de direitos e interesses, o direito à cidade pressupõe também os deveres que possibilitam realizar a política urbana, sejam eles do próprio Poder Público, sejam dos cidadãos ${ }^{11}$. Isso faz-se necessário porque quando se considera o âmbito urbano/ambiental, a separação absoluta do campo individual e do coletivo é impossível, pois "para realizar o direito à cidade, é necessário financiálo". Nesse sentido, os deveres fundamentais "guardam relação (...) com o princípio da subsidiariedade, exigindo dos integrantes do corpo-social a sua cota parte, no sentido de que mesmo o Estado Social não atua como uma espécie de segurador universal" (SARLET; FENSTERSEIFER apud REISDORFER, 2015 p.190).

Para a efetivação do direito à cidade, portanto, o particular não pode recolher-se ao senso comum expresso nas frases 'pago meus impostos' e 'voto a cada eleição' e exigir direitos como um mero cidadão descomprometido do Estado Liberal ou um simples usuário dos serviços do Estado Social, ou, ainda, súdito do Estado-Polícia. A realização do desenvolvimento urbano prescinde mais do que sua previsão legal. Como deveres fundamentais dos cidadãos, além da via tributária - impostos, taxas e contribuições de melhoria, estas últimas para reequilibrar a apropriação individual e coletiva dos benefícios urbanísticos decorrentes da atuação estatal - pode-se dar via participação ativa, como sujeito ativo e co-responsável pelos rumos da cidade, acompanhando e cobrando a responsabilização dos agentes públicos accountability.

\section{PLANEJAMENTO URBANO}

Tendo em vista a correlação entre cidadania, espaços públicos urbanos e Direito à Cidade, por fim resta tecer considerações acerca dos deveres do Poder Público, já que o Estado encontra-se em um lugar de decisão quanto à disponibilização de recursos para a execução de políticas públicas, projetos e obras em uma cidade. O planejamento público contemporâneo

\footnotetext{
11 "Somente com uma consideração adequada dos deveres fundamentais e dos custos dos direitos, poderemos lograr um estado em que as ideias de liberdade e de solidariedade não se excluam, antes se completem. Ou seja, somente com uma consideração adequada dos deveres fundamentais e dos custos dos direitos, poderemos desfrutar de um estado de liberdade e de um estado de liberdade a um preço moderado. Por isso, não podemos esquecer o que, com uma clarividência que ainda hoje impressiona, dizia Alexis de Tocqueville: 'a reclamação de direitos e a sua realização não é suficiente; os cidadãos também têm deveres”. (NABAIS, 2007, p.194)
} 
deveria tentar reduzir a injustiça social. No passado, ideias corbusianas ${ }^{12}$ ignoravam diferenças sociais, mas atualmente os conflitos explicitam-se e acenam para alternativas de vida na cidade.

Claro está que dentro de uma mesma cidade há consideráveis diferenças que terminam por refletir a desigualdade socioespacial. O Estado pode acentuar ou atenuar essa desigualdade, porque é o principal agente interventor (ou fomentador de intervenções) no espaço, ao captar receitas tributárias e deter grande poder de decisão sobre onde serão alocados os recursos, onde serão realizados investimentos de infraestrutura, normas para uso do solo, abertura de vias, etc, O espaço, pois, possui valor de uso e é nesse processo de agregar valor diferencial, mediados por processos políticos, conflitos e ideologias que se confrontam território e territorialidades.

Em uma sociedade desigual formada por cidades estruturadas na desigualdade socioespacial, a distribuição dos espaços livres e áreas verdes (parques e praças) se dá de forma bastante heterogênea e a qualidade ambiental de cada um deles é diretamente proporcional à renda da vizinhança. Discutir política e planejamento públicos nesses casos exige um conhecimento local e afetivo do território, caracterizando a situação urbana específica, a atuação dos diversos agentes na implantação e gestão de sistemas, sua configuração e as possibilidades de uso e apropriações que abrigam (PRETO, 2009). Ademais, o Estado deve precaver-se para ouvir e para fazer uma leitura subliminar de certas demandas, que perpassam os argumentos objetivos apresentados, já que muitas dessas demandas - inclusive para criação de parques e praças - são travestidas de uma preocupação com a preservação ambiental, mas têm na verdade outro propósito, como dificultar o acesso de determinados grupos à área em questão, "higienização", etc.

A análise urbana, para propiciar um bom diagnóstico e constituição de um bom subsídio para a proposição de políticas públicas, então, deve ser sensível aos diferentes atores, objetos, geografias, simbologias e temporalidades, reconhecendo e valorizando a diferença, as múltiplas formas de exclusão e segregação existentes nos espaços livres públicos (ALVARES; VAINER; QUEIROGA, 2008). Os diferentes também devem ter direito à cidade. A apropriação dos espaços da cidade por todos, além de um direito, é uma afirmação de cidadania.

\footnotetext{
12 A Carta de Atenas, elaborada durante o IV CIAM, em 1933 e publicada por Le Corbusier em 1941 sintetiza 4 elementos chave para o urbanismo: habitar, trabalhar, recrear-se (nas horas livres) e circular, pois até então o urbanismo focava-se somente em questões de circulação.
} 
Fato é que a margem de manobra do poder público quando a urbanização já se encontra consolidada é reduzida diante da propriedade privada da terra e dos altos custos de desapropriação; por outro lado, vazios urbanos teriam uma vocação como elemento central de políticas públicas de qualificação do ambiente urbano. Para além de propiciar maior experiência estética à cidade, valoriza-se o bem comum. De toda maneira, o direito à cidade não pode ser somente para determinado lugar, determinado grupo, não pode ser viável somente nas áreas centrais. Para além da acessibilidade, essa 'centralidade' deve ser levada a todos os espaços da cidade.

A história, definições e relações dos centros e suas periferias se confundem com a da urbanística moderna. Existe uma segregação espacial na cidade em função da renda dos indivíduos, e o processo de reprodução do capital indica os modos de ocupação do espaço e, em última análise, a configuração do espaço urbano. Pessoas com maiores rendas, no geral, tendem a residir em bairros arborizados, amplos, com infraestrutura completa, onde o preço da terra é alto e gastam menos tempo com locomoção. Já pessoas de renda menor tendem a habitar a periferia, comumente entendida como área densamente populosa, carente de infraestruturas e com preços de imóveis mais acessíveis, onde proliferam autoconstruções. Com isso gastam muito mais tempo com locomoção. A quem nem mesmo isso é possível, restam as favelas.

A área central consiste no foco principal da cidade e de sua hinterlândia. Ali se concentram as principais atividades comerciais, de serviços, da gestão pública e privada, e os terminais de transportes inter-regionais e intra-urbanos, destacando-se na paisagem pela sua verticalização (CORRÊA, 1989, p. 37). Para Balsas, "o que distingue o centro das cidades das zonas periféricas é a sua multifuncionalidade e a sua mistura orgânica de funções, podendo encontrar-se mercados públicos, centros de negócios, escolas e universidades, instituições de saúde e salões de beleza, locais para reuniões, galerias de arte, cultura e lazer; locais para visitar, transportes e áreas residenciais. No entanto, o seu principal papel é a venda a retalho. Um centro de cidade é mais que um centro comercial." (BALSAS, 1999, p. 53).

O consumo da cidade pode se dar por meio da troca - como no caso da habitação, transporte, infraestrutura, saúde, educação- pelo uso, sem a mediação do mercado, como o caso de bens de consumo produzidos pelo Estado (hospitais e escolas), ou onde a sociedade cria um uso possível (áreas de lazer, praças, etc) (CARLOS, 2015, p. 80). Nesse último caso, no geral, em áreas periféricas (e isso é verificável na área periférica de Belo Horizonte), os espaços públicos destinados ao lazer não se adequam ao tamanho da população local. Ademais, 
também há baixo nível de cobertura vegetal, resultado da pequena arborização das ruas, avenidas e outros espaços livres, já que, também, são poucos parques e praças nessas áreas. Em vários casos, esses espaços livres foram invadidos por favelas.

A regional Centro-Sul da cidade de Belo Horizonte, de maior renda e IDH, concentra a maior parte dos parques por habitante em quantidade e tamanho. A regional Noroeste conta com a menor quantidade de parques, e, pelas características da região (muito antiga e consolidada, com casas, sem grandes alterações no traçado com o passar dos anos) não há possibilidades fáceis e imediatas para criação novas de áreas de lazer. Nesse sentido, a regional Venda-Nova, no limite norte da cidade, com baixo IDH e poucos parques abertos ao público, conta com o maior potencial de expansão nesse quesito.

A distribuição dos espaços públicos - parques e praças - é claramente heterogênea na cidade. Assim, por um lado, podemos dizer que moradores de áreas periféricas são mais tolhidos no seu direito à cidade, uma vez que têm menos espaços públicos livres próximos de suas residências, o que implica menos possibilidades de lazer acessível e gratuito. Possuem menor renda familiar e menos cobertura vegetal ao redor e também nas ruas e avenidas, o que piora a qualidade de vida, pois essas áreas acabam por se transformarem em ilhas de calor. Além disso, fato também verificado em pesquisa em andamento, gastam grande tempo com locomoção, o que reduz a possibilidade de usufruto dos espaços disponíveis, além de tal fato potenciar maior alheamento à vida citadina e à participação e ao exercício da cidadania.

No que tange ao usufruto de parques e praças como locais de encontro, lazer e ócio, em que pese a distribuição desigual destes na cidade de Belo Horizonte, em ambos, nos do centro e das periferias, observa-se grande frequência de usuários, na periferia principalmente nos parques. Entretanto, o fator proximidade do local de residência apareceu como bastante relevante nas entrevistas realizadas, o que faz com que os frequentadores pertençam a grupos bastante homogêneos.

\section{À GUISA DE CONCLUSÃO}

O acesso e a pertença à cidade e, consequentemente, o exercício da cidadania em todas as suas formas, convencionais ou não, por parte de grupos marginalizados e/ou suburbanos pode encontrar vários óbices à sua efetivação. Conforme demonstra pesquisa de campo em andamento nos parques e praças de Belo Horizonte, o número de espaços públicos que propiciam o encontro entre as pessoas e favoreçam as trocas é menor em áreas mais 
afastadas do centro, a qualidade desses espaços deixa muitas vezes a desejar, há menos heterogeneidade entre os frequentadores, as pessoas também dispõem de menos disponibilidade para frequentá-los uma vez que o movimento pendular casa-trabalho consome grande parte do tempo livre. Além disso, tais pessoas tendem a ter menos capital econômico, cultural, social e mobilização congnitiva, o que também dificulta a própria luta pelo acesso a direitos, pelo acesso e pertença à cidade, ou seja, pode-se dizer que esses fatores dificultam o exercício da cidadania.

O Estado, tampouco, cumpre bem seu papel de promotor da justiça social ao favorecer o exercício da cidadania e o usufruto da cidade a todos pois, como observado, é em grande parte composto por grupos que já usufruem de certos privilégios e, ao realizar seu planejamento/ações, considerando a composição dos interesses em jogo - com opções técnicas, políticas e jurídicas - e o poder dos atores envolvidos, dá preferência de alguns elementos/áreas em detrimento de outros.

\section{REFERÊNCIAS BIBLIOGRÁFICAS}

ALVARES, Lucia Capanema, VAINER, Carlos Bernardo, QUEIROGA, Eugênio Fernandes. Conflitos urbanos e espaços livres públicos - construção de uma metodologia para estudos comparativos, 2008.

ARENDT, Hannah. Origens do totalitarismo. São Paulo: Cia. Das Letras, 1989.

ARISTÓTELES. Política. Martim Claret. Lelivros (acesso online).

BALSAS, Carlos José Lopes. Urbanismo comercial em Portugal e a revitalização do centro das cidades. Lisboa: Ministério da Economia, 1999.

BRASIL, Flávia de Paula Duque. Apropriação das praças como espaço de lazer, cultura e cidadania. In.: ANAIS do V Encontro Nacional da ANPUR 1993 pp 160-178.

CALOR, Mara Suzana. Criação de áreas verdes em ambientes urbanos - caso: Parque da Integração. In.: MANTOVANI, Marta; GLEZER, Raquel. Parques urbanos: preservação e lazer nas áreas públicas. São Paulo: Planetaterra, 2009.

CARLOS, Ana Fani Alessandri. A cidade. 9 ed. SP: Contexto, 2015.

CORRÊA, Roberto Lobato. O Espaço Urbano, São Paulo, Editora Ática S.A. Série Princípios, 1989.

COVRE, Maria de Lourdes Manzine. O que é cidadania. 3. ed. São Paulo: Brasiliense, 1995. 
FIGUEROA, Abilio Vergara. Espacio, lugar y ciudad: etnografía de um parque. In.: HIERNAUX, Daniel; LINDON, Alicia; AGUILAR, Miguel Ángel (Coords). Lugares e Imaginarios em la Metropolis. Anthropos, Mexico, Rubi, Barcelona, 2006.

FORTUNA, C; SILVA, A. A cidade do lado da cultura: espacialidades sociais e modalidades de intermediação cultural. In.: SANTOS, B de S. A globalização e as ciências sociais. SP: Cortez, 2002.

KAPP, Silke. Direito ao espaço cotidiano: moradia e autonomia no plano de uma metrópole. In.: Cad. Metrop, SP, v.14, n.28, 2012.

LAFER, Celso. A reconstrução dos direitos humanos - um diálogo com o pensamento de Hannah Arendt. São Paulo, Cia. Das Letras, 1988.

LEFEBVRE, Henri. The production of space. Oxford/Cambridge, Blackwell, 1991, pp 165 e 320. La significacion de la comuna, 1962.

MACHADO, Rodrigo. A Educação ambiental na práxis cotidiana a partir da experimentação da agenda 21 do pedaço: um olhar sobre o Conselho Gestor do Parque Vila Guilherme. In.: MANTOVANI, Marta; GLEZER, Raquel. Parques urbanos: preservação e lazer nas áreas públicas. São Paulo: Planetaterra, 2009.

MARICATO, Ermínia. O impasse da política urbana no Brasil. Petrópolis, Vozes, 2011.

MONTE-MÓR, Roberto Luís de Melo. O que é o urbano, no mundo contemporâneo. Belo Horizonte: Cedeplar, 2006. Texto para discussão n. 281 a partir das ideias de Lefevbvre.

NABAIS, José Casalta. Por uma liberdade com responsabilidade: estudos sobre direitos e deveres fundamentais. Coimbra: Coimbra Ed., 2007.

PRETO, Maria Helena de F. Sistema de Espaços Livres Públicos - uma contribuição ao planejamento local. Dissertação (mestrado). Faculdade de Arquitetura e Urbanismo da USP. São Paulo. 2009.

REISDORFER, Guilherme. Definição e concretização do Direito à Cidade: entre os direitos e deveres fundamentais. Revista de Direito Administrativo Contemporâneo, 2015.

ROBBA, F.; MACEDO, S.S. Praças brasileiras. São Paulo: Edusp/ Imprensa Oficial do Estado, Coleção Quapá, 2002.

SARLET, Ingo Wolfgang; FENSTERSEIFER, Thiago. Direito Constitucional Ambiental. Constituição, direitos fundamentais e proteção do ambiente. 4ed ver. e atual. São Paulo: Ed.RT, 2014 apud.

REISDORFER, Guilherme. Definição e concretização do Direito à Cidade: entre os direitos e deveres fundamentais. Revista de Direito Administrativo Contemporâneo, 2015.

SENNET, Richard. Les Tyrannies de l'intimité. Paris:Seuil, 1974 apud SERPA, Angelo. O espaço público na cidade contemporânea. 2ed.São Paulo: Contexto, 2014.

SOUZA, Jessé. A Tolice da Inteligência Brasileira: ou como o país se deixa manipular pela elite. São Paulo: Leya, 2015. 
VIEIRA, Monica Brito. O Espaço urbano e a arquitetura da cidadania. In.: CABRAL, Manuel Villaverde; SILVA, Filipe Careira; SARAIVA, Tiago. Cidade e Cidadania. Governança urbana e participação cidadã em perspectiva comparada. Lisboa: ICS, 2008.

Trabalho enviado em 22 de junho de 2017.

Aceito em 09 de setembro de 2017. 